\title{
Agreement of Ultrasound Measures with POP-Q in Patients with Pelvic Organ Prolapse
}

\author{
Arvin $\operatorname{Arian}^{1}$, Zinat Ghanbari ${ }^{2,{ }^{*}}$, Nastaran Chegini $^{2}$ and Melina Hosseiny ${ }^{1, * *}$ \\ ${ }^{1}$ Advanced Diagnostic and Interventional Radiology Research Center (ADIR), Imam Khomeini Hospital, Tehran University of Medical Sciences, Tehran, Iran \\ ${ }^{2}$ Department of Obstetrics and Gynecology, Imam Khomeini Hospital, Tehran University of Medical Sciences, Tehran, Iran \\ "Corresponding author: Zinat Ghanbari, Department of Obstetrics and Gynecology, Imam Khomeini Hospital, Tehran University of Medical Sciences, Tehran, Iran. Email: \\ drz_ghanbari@yahoo.com \\ Corresponding author: Melina Hosseiny, Advanced Diagnostic and Interventional Radiology Research Center (ADIR), Imam Khomeini Hospital, Tehran University of Medical \\ Sciences, Keshavarz Blvd., Tehran, Iran. Tel: +98-9122771874, Email: melina2.hosseiny@gmail.com
}

Received 2018 March 09; Revised 2018 July 04; Accepted 2018 July 14.

\begin{abstract}
Background: Ultrasound has emerged as a valuable complimentary tool for assessment of pelvic organ prolapse (POP).

Objectives: The present study aimed to evaluate the correlation between ultrasound measures and clinical staging in patients with suspected POP.

Patients and Methods: Forty women with clinical suspicion of POP were enrolled in this cross-sectional study between November 2011 and April 2012. Pelvic organ prolapse quantification (POP-Q) system was used for clinical staging. Perineal ultrasound was performed both at rest and during Valsalva maneuver after proper preparation. On mid sagittal view, two reference lines were drawn; midpelvic line (MPL) was defined as the inferior horizontal tangent of symphysis pubis and $\mathrm{H}$ line was drawn from the most inferior part of symphysis pubis to the anorectal junction. Spearman's correlation coefficient and Kappa coefficient of agreements were used for statistical analysis.

Results: Forty women with the mean age of $49.9 \pm 10.07$ years were enrolled. Excellent correlation was seen between MPL and $\mathrm{H}$ line (rho $=0.91,0.93$ and 0.88 in anterior, apical and posterior compartments, respectively). POP-Q had good-to-excellent correlation with ultrasound ( $\mathrm{rho}=0.84,0.78$ and 0.63 for $\mathrm{H}$ line and $\mathrm{rho}=0.89,0.82,0.71$ for MPL in anterior, apical and posterior compartments respectively). In anterior and apical compartments, high agreement was seen between clinical and ultrasound staging methods when grouping patients to no prolapse/mild vs. moderate/severe. In the posterior compartment, this agreement was significant when grouping was done based on the presence or absence of POP.

Conclusion: Ultrasound has high correlation with POP-Q staging in all compartments for staging of pelvic organ prolapse. Ultrasound might be useful in the diagnosis of pop in those with negative clinical examination.
\end{abstract}

Keywords: Pelvic Organ Prolapse, Trans Perineal Ultrasonound, Physical Examination, POP-Q, Agreement

\section{Background}

Pelvic organ prolapse (POP) is a highly prevalent disorder in women above the age of 50 . The disorder leads to bowel and bladder dysfunction and a poor quality of life (1). The proper management of this entity is a major challenge for gynecologists as it leads to surgery in $11 \%$ of women during their lifetime with $30 \%$ requiring reoperation (2). Physical examination provides basic information about surface anatomy. To standardize clinical examination, the international continence society (ICS) recommends the use of a site-specific system called the pelvic organ prolapse quantification (POP-Q) $(3,4)$.

As complementary tools, various imaging techniques have been developed for better assessment of this disorder (5). Fluoroscopy is unpleasant and carries the risk of radi- ation. Magnetic resonance imaging is costly and may underestimate the extent of enterocele and cystocele (6).

Ultrasound (US) is the most available imaging tool in urogynecology as it has the advantages of providing real time information, no radiation exposure and low costs (79).

Various forms of POP have been described. Features of transperineal ultrasound show moderate-to-good correlation with physical examination in anterior compartment POP, while variable correlations for central and posterior compartment POP have been reported $(10,11)$. The present study was conducted to assess the correlation between clinical examination and ultrasound. Moreover, the agreement between transperineal ultrasonography staging and clinical staging were examined. 


\section{Objectives}

The present study was conducted to assess the correlation between clinical examination and ultrasound. Moreover, the agreement between transperineal ultrasonography staging and clinical staging were examined.

\section{Patients and Methods}

This cross-sectional study was carried out on forty women who were referred to the pelvic floor clinic between November 2011 and April 2012. Patients with a compatible history of pelvic organ prolapse (abnormal sensation of fullness or pressure in the vagina, protruding cervix or sensation of mass protrusion with normal ultrasound, difficulty in coitus, defecation or voiding and lower abdominal discomfort) were included. Those who were unable to perform Valsalva maneuver were excluded. The institutional review board and local ethics committee at the university approved this study. Written informed consent was obtained from all participants after providing detailed description of the study method.

Clinical examination was performed with the patient lying in the supine position after full voiding. Clinical assessments were performed by two gynecologists who were experienced in the assessment of the POP using the most widely accepted clinical staging method, pelvic organ prolapse quantification (POP-Q). The coefficient of variation for interobserver variability of assessments between two gynecologists was not significant on examination of 20 patients with POP. Maximal descent of the pelvic organ was determined in the cervix, anterior and posterior vaginal walls. For each patient, maximal pelvic organ descent in the anterior (cystocele), middle or apical (cervical prolapse) and posterior (rectocele/enterocele) compartments were determined based on the aforementioned methods separately. Then, all patients underwent transperineal ultrasonography by an experienced radiologist. All three operators were blinded to each other's examination results. Based on the POP-Q grading, the results of clinical examination were categorized as negative/no prolapse (distance $<-10 \mathrm{~mm})$, mild $(-10 \leq$ distance $<10 \mathrm{~mm})$, moderate $(10 \leq$ distance $<$ total vaginal length [TVL]-2) and severe (TVL-2 $\leq$ distance $<$ TVL) (12). Then, all patients underwent transperineal ultrasonography by an experienced radiologist. All three operators were blinded to each other's examination results.

\subsection{Ultrasound Technique}

Ultrasound was performed with the woman in the dorsal lithotomy position using a 3.5 - $5 \mathrm{MHz}$ curved array transducer (Medison, Accuvix V20). Patients were asked to void and if required, to empty rectum before examination. Parting the labia was carried out to improve image quality. Powder-free gloves wee used to cover the transducer.
Examination was performed at rest and on maximum Valsalva. Standard mid-sagittal, two-dimensional gray scale views that contained symphysis pubis, bladder neck and urethra, vagina, rectum and anal canal were obtained. Two different reference lines were used, named as midpelvic line (MPL) and $\mathrm{H}$ line (Figure 1). MPL was defined as the inferior horizontal tangent of symphysis pubis (7), while $\mathrm{H}$ line was drawn from the inferior border of symphysis pubis to the anorectal junction (13). The maximum distance of pelvic organ prolapse from each reference line was measured in millimeter. Pelvic organ stations were given negative values if located internally relative to the reference line and positive values if located in external location related to the reference line.

Then, the prolapse was categorized to four groups of negative (prolapse above to reference line), mild (distance of prolapse to reference line lower than $20 \mathrm{~mm}$ or prolapse in the same level with reference line), moderate (distance of prolapse to reference line equal or greater than $20 \mathrm{~mm}$ and lower than $40 \mathrm{~mm}$ ), and severe (distance of prolapse to reference line equal or greater than $40 \mathrm{~mm}$ ).

\subsection{Data Analysis}

SPSS for Windows version 16.0 (SPSS Inc. Released 2007. Chicago, SPSS Inc) was used to perform statistical analysis. Using spearman's rank correlation coefficient the agreements between the values derived from the described methods of physical and ultrasonographic assessments were determined. A Spearman's correlation coefficient (rho) of more than 0.80 denotes excellent correlation, between 0.80 and 0.60 means good correlation, between 0.60 and 0.40 means moderate correlation, and below 0.40 points to poor correlation, respectively.

Agreement of ultrasound grading with clinical grading was assessed by Kappa coefficient of agreement in three compartments of anterior, apex and posterior. In each instance, we classified the grading results into two groups (prolapse positive vs. negative, prolapse negative/mild vs. prolapse moderate/severe). Then we calculated the Kappa coefficients in all three compartments separately. All of these agreements were done for POP-Q vs. sonographic H-Line, POP-Q vs. sonographic MP Line, and finally sonographic H-Line vs. MP Line.

\section{Results}

Forty women with the mean age of $49.9 \pm 10.07$ (range: 29 -75) were included. Participants had a mean parity of 3.4 \pm 1.72 (range: 1 - 9). Figures 1 and 2 demonstrate examples of pelvic organ prolapse on ultrasound study.

Both ultrasound measurement methods using MPL and $\mathrm{H}$ line had excellent agreement with each other in all compartments ( $\mathrm{rho}=0.91,0.93$ and 0.88 in anterior, apical and posterior compartments, respectively).

Table 1 demonstrates correlations between clinical and sonographic measures in all the three compartments in 

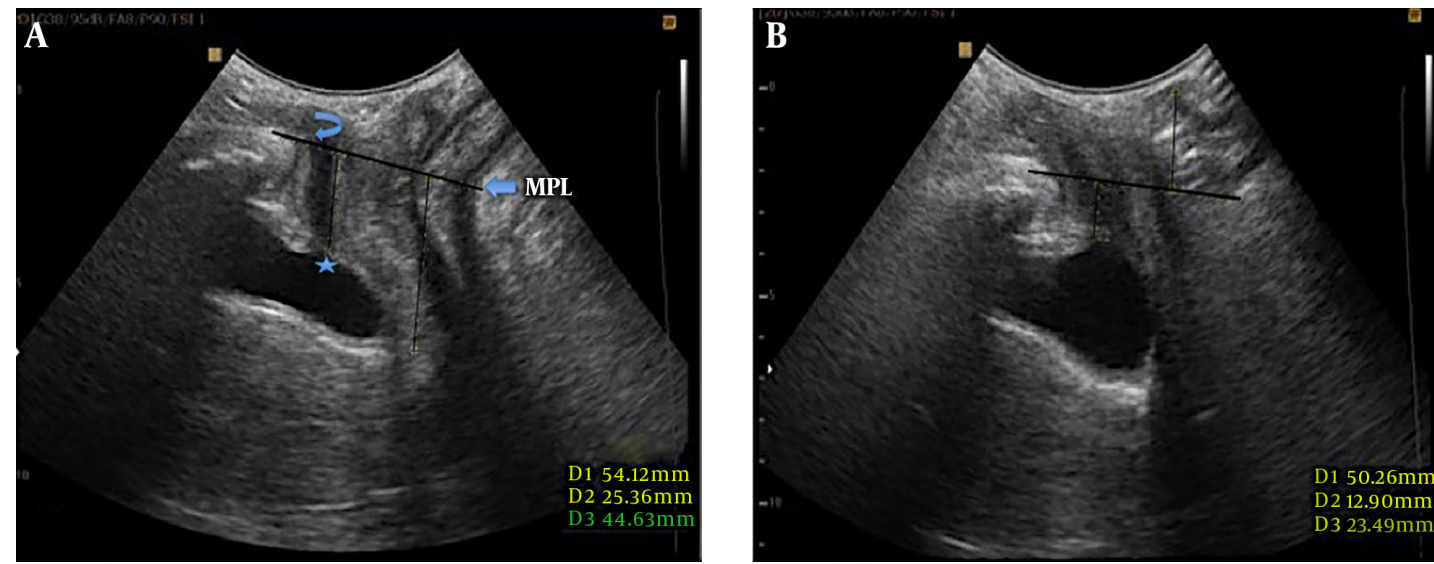

Figure 1. A 36-year-old female with difficulty in defecation. A, Midsagittal plane of the pelvic floor at rest. Position of the bladder neck (Asterisk) and inferior margin of symphysis pubis (curved arrow) are shown. B, The same plane during Valsalva maneuver. The bladder neck is still above the reference midpelvic line (MPL), however the anorectal angle descent below the reference line is visualized along with protrusion of the anterior rectal wall. Findings are compatible with anterior rectocele.
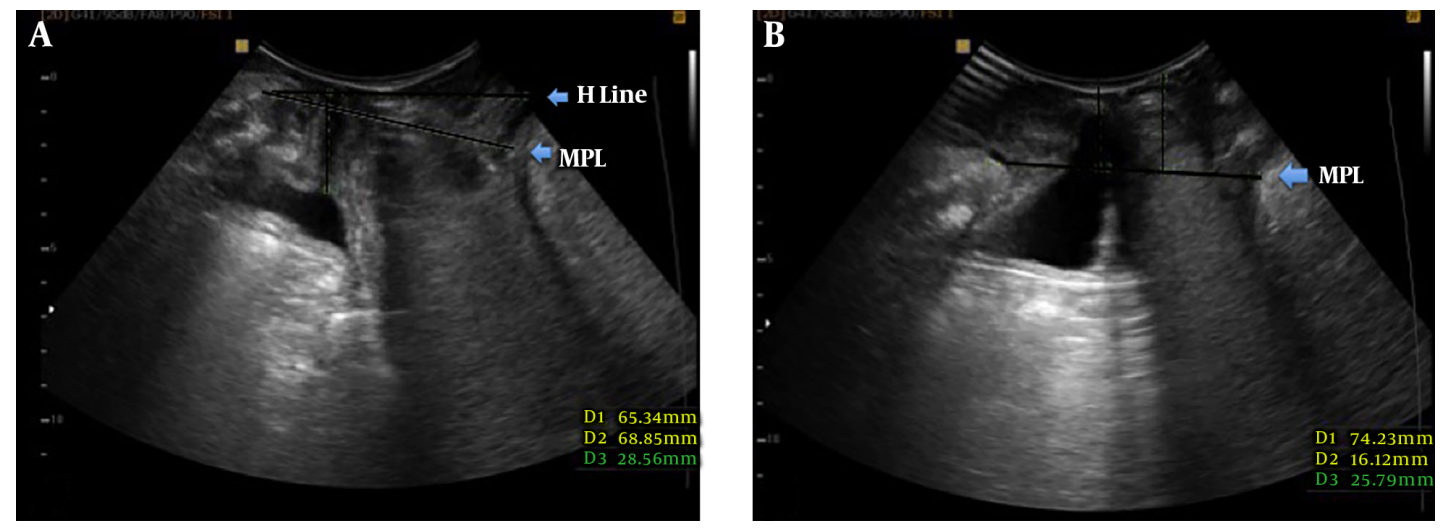

Figure 2. A, The midsagittal image of the pelvic floor at rest shows the position of the bladder neck above the midpelvic line (MPL). Anterior protrusion of the anterior rectal wall is also seen. B, The same plane in maximum Valsalva maneuver shows bladder neck descent below MPL (16 mm) consistent with cystocele. The anterior rectal wall is seen in a lower position compared to the image at rest.

detail. POP-Q had good-to-excellent correlation with both ultrasound measures especially in the anterior and apical compartments. Compared to H-line, the use of MPL as the reference line seems to result in relatively stronger correlation (although not statistically significant) between ultrasonography and POP-Q.

High agreement was seen between clinical and ultrasound staging systems as shown in Tables 2 and 3. In anterior and apical compartments, the agreement was considerable when grouping patients to no prolapse/mild vs. moderate/severe. In the posterior compartment, the agreement was significant when grouping was carried out based on the presence or absence of pop. This pattern was consistent by using either ultrasound reference line as shown by high agreement $(>0.7)$ between MPL and $\mathrm{H}$ line for staging of POP (Table 4).

Iran J Radiol. 2018; 15(4):e68461.
Table 1. Correlations Between Ultrasound and Clinical Assessment in All Patients With POP Using Spearman's Correlation Coefficient

\begin{tabular}{|ccc}
\hline & POP-Q & Pvalue \\
\hline Anterior compartment & & \\
H line & 0.84 & $<0.0001$ \\
MPL & 0.89 & $<0.0001$ \\
Apical compartment & & \\
\hline H line & 0.78 & $<0.0001$ \\
MPL & 0.82 & $<0.0001$ \\
Posterior compartment & & \\
\hline H line & 0.63 & $<0.0001$ \\
\hline MPL & 0.71 & $<0.0001$ \\
\hline
\end{tabular}

Abbreviations: MPL, midpelvic line; POP-Q, pelvic organ prolapse quantification.

\section{Discussion}

Imaging has turned into an essential tool in the work up of pelvic organ prolapse. Ultrasound might be the 


\begin{tabular}{|c|c|c|c|c|c|}
\hline \multirow[t]{2}{*}{ Compartment } & \multicolumn{2}{|c|}{ Concordant $^{\mathrm{a}}$} & \multicolumn{2}{|c|}{ Discordant $^{\mathrm{a}}$} & \multirow[t]{2}{*}{ Kappa [95\% CI] } \\
\hline & Both positive & Both negative & $\begin{array}{l}\text { POP-Q positive } \\
\text { sonography } \\
\text { negative }\end{array}$ & $\begin{array}{l}\text { POP-Q negative } \\
\text { sonography } \\
\text { positive }\end{array}$ & \\
\hline \multicolumn{6}{|l|}{ Anterior } \\
\hline Prolapse presence versus prolapse absent & $28(70)$ & $3(7.5)$ & $4(10)$ & $5(12.5)$ & $0.26[0-62]$ \\
\hline $\begin{array}{l}\text { Moderate or severe prolapse versus mild } \\
\text { prolapse or negative prolapse }\end{array}$ & $12(30)$ & $23(57.5)$ & $1(2.5)$ & $4(10)$ & $0.73[0.51-0.95]$ \\
\hline \multicolumn{6}{|l|}{ Apex } \\
\hline Prolapse presence versus prolapse absent & $15(37.5)$ & $13(32.5)$ & $7(17.5)$ & $5(12.5)$ & $0.4[0.18-0.68]$ \\
\hline $\begin{array}{l}\text { Moderate or severe prolapse versus mild } \\
\text { prolapse or negative prolapse }\end{array}$ & $4(10)$ & $33(82.5)$ & 0 & $3(7.5)$ & $0.69[0.36-1]$ \\
\hline \multicolumn{6}{|l|}{ Posterior } \\
\hline Prolapse presence versus prolapse absent & $28(71.8)$ & $6(15.4)$ & 0 & $5(12.8)$ & $0.63[0.35-0.91]$ \\
\hline $\begin{array}{l}\text { Moderate or severe prolapse versus mild } \\
\text { prolapse or negative prolapse }\end{array}$ & $4(10.3)$ & $18(46.2)$ & $2(5.1)$ & $15(38.5)$ & $0.12[0-0.34]$ \\
\hline \multicolumn{6}{|c|}{$\begin{array}{l}\text { Abbreviations: CI, confidence interval;POP-Q, pelvic organ prolapse quantification. } \\
{ }^{a} \text { Values are expressed as No. (\%). }\end{array}$} \\
\hline \multirow[t]{2}{*}{ Compartment } & \multicolumn{2}{|c|}{ Concordant $^{\mathrm{a}}$} & \multicolumn{2}{|c|}{ Discordant $^{\mathbf{a}}$} & Kappa $[95 \%$ CI] \\
\hline & Both positive & Both negative & $\begin{array}{l}\text { POP-Q positive } \\
\text { sonography } \\
\text { negative }\end{array}$ & $\begin{array}{l}\text { POP-Q negative } \\
\text { sonography } \\
\text { positive }\end{array}$ & \\
\hline \multicolumn{6}{|l|}{ Anterior } \\
\hline Prolapse presence versus prolapse absent & $28(70)$ & $6(15)$ & $4(10)$ & $2(5)$ & $0.57[0.27-0.88]$ \\
\hline $\begin{array}{l}\text { Moderate or severe prolapse versus mild } \\
\text { prolapse or negative prolapse }\end{array}$ & $11(27.5)$ & $25(62.5)$ & $2(5)$ & $2(5)$ & $0.77[0.56-0.98]$ \\
\hline \multicolumn{6}{|l|}{ Apex } \\
\hline Prolapse presence versus prolapse absent & $14(35)$ & $11(27.5)$ & $8(20)$ & $7(17.5)$ & $0.25[0-0.55]$ \\
\hline $\begin{array}{l}\text { Moderate or severe prolapse versus mild } \\
\text { prolapse or negative prolapse }\end{array}$ & $4(10)$ & $35(87.5)$ & 0 & $1(2.5)$ & $0.88[0.64-1]$ \\
\hline \multicolumn{6}{|l|}{ Posterior } \\
\hline Prolapse presence versus prolapse absent & $28(71.8)$ & $7(17.9)$ & 0 & $4(10.3)$ & $0.72[0.46-0.97]$ \\
\hline $\begin{array}{l}\text { Moderate or severe prolapse versus mild } \\
\text { prolapse or negative prolapse }\end{array}$ & $2(5.1)$ & $25(64.1)$ & $4(10.3)$ & $8(20.5)$ & $0.07[-0.2-0.39]$ \\
\hline \multicolumn{6}{|c|}{$\begin{array}{l}\text { Abbreviations: CI, confidence interval;POP-Q, pelvic organ prolapse quantification. } \\
{ }^{a} \text { Values are expressed as No. (\%). }\end{array}$} \\
\hline \multirow[t]{2}{*}{ Compartment } & \multicolumn{2}{|c|}{ Concordant $^{\mathrm{a}}$} & \multicolumn{2}{|c|}{ Discordant $^{\mathrm{a}}$} & Kappa $[95 \%$ CI] \\
\hline & Both positive & Both negative & $\begin{array}{l}\text { POP-Q positive } \\
\text { sonography } \\
\text { negative }\end{array}$ & $\begin{array}{l}\text { POP-Q negative } \\
\text { sonography } \\
\text { positive }\end{array}$ & \\
\hline \multicolumn{6}{|l|}{ Anterior } \\
\hline Prolapse presence versus prolapse absent & $30(75)$ & $7(17.5)$ & 0 & $3(7.5)$ & $0.78[0.54-1]$ \\
\hline $\begin{array}{l}\text { Moderate or severe prolapse versus mild } \\
\text { prolapse or negative prolapse }\end{array}$ & $12(30)$ & $23(57.5)$ & $1(2.5)$ & $4(10)$ & $0.73[0.51-0.95]$ \\
\hline \multicolumn{6}{|l|}{ Apex } \\
\hline Prolapse presence versus prolapse absent & $19(47.5)$ & $18(45)$ & $2(5)$ & $1(2.5)$ & $0.85[0.69-1]$ \\
\hline $\begin{array}{l}\text { Moderate or severe prolapse versus mild } \\
\text { prolapse or negative prolapse }\end{array}$ & $5(12.5)$ & $33(82.5)$ & 0 & $2(5)$ & $0.81[0.55-1]$ \\
\hline \multicolumn{6}{|l|}{ Posterior } \\
\hline Prolapse presence versus prolapse absent & $32(82.1)$ & $6(15.4)$ & 0 & $1(2.6)$ & $0.91[0.73-1]$ \\
\hline $\begin{array}{l}\text { Moderate or severe prolapse versus mild } \\
\text { prolapse or negative prolapse }\end{array}$ & $20(51.3)$ & $10(25.6)$ & 0 & $9(23.1)$ & $0.53[0.3-0.77]$ \\
\hline
\end{tabular}

Abbreviations: MP, midpelvic ; CI, confidence interval.

${ }^{\mathrm{a}}$ Values are expressed as No. (\%). 
cheapest and the most available imaging tool for assessment of pelvic floor descent (14). Various methods of ultrasound exam are suggested for evaluation of POP including transvaginal, introital (15) and transperineal ultrasound. Compared to physical examination, ultrasound is more accurate for determination of the type of prolapse by demonstrating the prolapsed organ. True and false rectocele can be differentiated using ultrasound by showing of a true fascial defect in the former and isolated perineal hypermobility without fascial deformity in the latter (7). Moreover, ultrasound provides a quantitative measure of the prolapse. Bladder neck position (16), mobility (17) and bladder wall thickness (18) can be reliably assessed by perineal ultrasound. Color Doppler ultrasound has been used to evaluate urine leakage (19). The technique of perineal ultrasound is not hard to learn and can be used by simple ultrasound equipment by radiologists.

Magnetic resonance imaging has an increasing role for this purpose with the advantages of providing a multiplanar imaging and high soft tissue resolution.13 MRI, however, is expensive and needs the patient's complete cooperation. Moreover, technical logistics and ultrafast acquisitions are required to obtain an optimal image. A large percentage of women will not carry out an appropriate contraction of pelvic muscles when asked (20).

This study compared the strength of two separate reference lines in ultrasound exam. MPL have been used in various studies of POP ultrasound. $\mathrm{H}$ line is the reference line mainly used in MRI of POP. Both MPL and H line showed strong correlation with POP-Q staging. The use of MPL might be more feasible by radiologists in a standard perineal ultrasound exam.

Several instances of mismatch were seen between POP$Q$ and ultrasound staging. In the anterior and central compartments, disagreement occurred mainly on staging to either no prolapse or mild prolapse. While in the posterior compartment, the mismatch was mainly in categorizing mild or moderate prolapse. Missing mild prolapse might not have practical effects on choosing treatment, as surgery is not usually required for those with mild prolapse. Therefore, ultrasound seems to be more valuable in anterior and central compartments, as it could more reliably delineate individuals with moderate or severe prolapse, while in the posterior compartment, it has poor agreement with POP-Q for staging moderate/severe prolapse. On the other hand, in all compartments, mismatch mainly occurred due to individuals having negative POP$\mathrm{Q}$ with positive ultrasound. This might reflect the higher power of ultrasound in diagnosis of patients with hidden prolapse on clinical examination. This finding needs to be assessed in further studies on individuals with probable hidden pelvic organ prolapse.

Dietz et al. were the first to assess the association between measures of perineal ultrasonography with international continence society (ICS) prolapse assessment system. They found a good correlation in the anterior ( $\mathrm{r}$ :
0.72) and central (r: 0.77) compartments, while a poor correlation was observed in the posterior compartment ( $\mathrm{r}$ : 0.53) (10). They proposed that clinical examination might not be accurate as it is based on vaginal landmarks rather than bony landmarks of ultrasound. Moreover, the use of speculum in clinical examination might affect patient's co-operation. Another evaluation on agreement between POP-Q and ultrasound staging showed moderate correlation in the anterior compartment $(r=0.58)$, but poor agreement in the posterior compartment (11).

This study was subject to several limitations. First and most important, there is no gold standard for diagnosis of patients with POP. Neither clinical examination, nor surgery is the gold standard for this purpose. This study was based on comparison of two most available clinical and ultrasound techniques and not compared to any gold standard. Second, the frequency of individuals with severe prolapse was low in both clinical examination and ultrasound.

In conclusion, this study showed high agreement between clinical staging and POP-Q and ultrasound examination. Ultrasound seems to be more powerful in delineating mild prolapse from moderate/severe prolapse in anterior and apical compartments. Ultrasound might be more powerful than clinical examination in the diagnosis of POP in those not having prolapse on clinical examination.

\section{Footnotes}

Authors' Contributions: None Declared.

Financial Disclosure: None Declared.

Funding/Support: None Declared.

\section{References}

1. Machin SE, Mukhopadhyay S. Pelvic organ prolapse: review of the aetiology, presentation, diagnosis and management. Menopause Int. 2011;17(4):132-6. doi: 10.1258/mi.2011.011108. [PubMed: 22120945].

2. Olsen AL, Smith VJ, Bergstrom JO, Colling JC, Clark AL. Epidemiology of surgically managed pelvic organ prolapse and urinary incontinence. Obstet Gynecol. 1997;89(4):501-6. doi: 10.1016/S0029-7844(97)00058-6. [PubMed: 9083302].

3. Bump RC, Mattiasson A, Bo K, Brubaker LP, DeLancey JO, Klarskov P, et al. The standardization of terminology of female pelvic organ prolapse and pelvic floor dysfunction. Am J Obstet Gynecol. 1996;175(1):107. [PubMed: 8694033].

4. Hall AF, Theofrastous JP, Cundiff GW, Harris RL, Hamilton LF, Swift $\mathrm{SE}$, et al. Interobserver and intraobserver reliability of the proposed International Continence Society, Society of Gynecologic Surgeons, and American Urogynecologic Society pelvic organ prolapse classification system. Am J Obstet Gynecol. 1996;175(6):1467-70. discussion 1470-1. [PubMed: 8987926].

5. Stoker J, Halligan S, Bartram CI. Pelvic floor imaging. Radiology. 2001;218(3):621-41. doi: 10.1148/radiology.218.3.r01mr26621. [PubMed: 11230632].

6. Kelvin FM, Maglinte DD, Hale DS, Benson JT. Female pelvic organ prolapse: a comparison of triphasic dynamic MR imaging and triphasic fluoroscopic cystocolpoproctography. AJR Am J Roentgenol. 2000;174(1):81-8. doi: 10.2214/ajr.174.1.1740081. [PubMed: 10628459]. 
7. Dietz HP. Ultrasound imaging of the pelvic floor. Part I: twodimensional aspects. Ultrasound Obstet Gynecol. 2004;23(1):80-92. doi: 10.1002/uog.939. [PubMed: 14971006].

8. Beer-Gabel M, Teshler M, Barzilai N, Lurie Y, Malnick S, Bass D, et al. Dynamic transperineal ultrasound in the diagnosis of pelvic floor disorders: pilot study. Dis Colon Rectum. 2002;45(2):239-45. discussion 2458. [PubMed: 11852339].

9. Dietz HP. Ultrasound imaging of the pelvic floor. Part II: threedimensional or volume imaging. Ultrasound Obstet Gynecol. 2004;23(6):615-25. doi: 10.1002/uog.1072. [PubMed: 15170808].

10. Dietz HP, Haylen BT, Broome J. Ultrasound in the quantification of female pelvic organ prolapse. Ultrasound Obstet Gynecol. 2001;18(5):5114. doi: 10.1046/j.0960-7692.2001.00494.x. [PubMed: 11844174].

11. Broekhuis SR, Kluivers KB, Hendriks JC, Futterer JJ, Barentsz JO, Vierhout ME. POP-Q, dynamic MR imaging, and perineal ultrasonography: do they agree in the quantification of female pelvic organ prolapse? Int Urogynecol J Pelvic Floor Dysfunct. 2009;20(5):541-9. doi: 10.1007/s00192-009-0821-1. [PubMed: 19221680].

12. Persu C, Chapple CR, Cauni V, Gutue S, Geavlete P. Pelvic Organ Prolapse Quantification System (POP-Q) - a new era in pelvic prolapse staging. J Med Life. 2011;4(1):75-81. [PubMed: 21505577]. [PubMed Central: PMC3056425].

13. Pannu HK, Kaufman HS, Cundiff GW, Genadry R, Bluemke DA, Fishman EK. Dynamic MR imaging of pelvic organ prolapse: spectrum of abnormalities. Radiographics. 2000;20(6):1567-82. doi: 10.1148/radiographics.20.6.g00nv311567. [PubMed: 11112811]
14. Dietz HP. Pelvic floor ultrasound in prolapse: what's in it for the surgeon? Int Urogynecol J. 2011;22(10):1221-32. doi: 10.1007/s00192-0111459-3. [PubMed: 21656320].

15. Tunn R, Petri E. Introital and transvaginal ultrasound as the main tool in the assessment of urogenital and pelvic floor dysfunction: an imaging panel and practical approach. Ultrasound Obstet Gynecol. 2003;22(2):205-13. doi: 10.1002/uog.189. [PubMed: 12905521].

16. Schaer GN, Koechli OR, Schuessler B, Haller U. Perineal ultrasound for evaluating the bladder neck in urinary stress incontinence. Obstet Gy necol.1995;85(2):220-4. doi:10.1016/0029-7844(94)00369-O. [PubMed: 7824234].

17. Dietz HP, Clarke B, Herbison P. Bladder neck mobility and urethral closure pressure as predictors of genuine stress incontinence. Int Urogynecol J Pelvic Floor Dysfunct. 2002;13(5):289-93. doi: 10.1007/s001920200063. [PubMed: 12355287].

18. Khullar V, Cardozo LD, Salvatore S, Hill S. Ultrasound: a noninvasive screening test for detrusor instability. Br J Obstet Gynaecol. 1996;103(9):904-8. [PubMed: 8813311].

19. Dietz HP, McKnoulty L, Clarke B. Translabial color Doppler for imaging in urogynecology: a preliminary report. Ultrasound Obstet Gynecol. 1999;14(2):144-7. doi: 10.1046/j.1469-0705.1999.14020144.x. [PubMed 10492875].

20. Bump RC, Hurt WG, Fantl JA, Wyman JF. Assessment of Kegel pelvic muscle exercise performance after brief verbal instruction. Am J Obstet Gynecol. 1991;165(2):322-7. discussion 327-9. [PubMed: 1872333]. 